\title{
Implication from Incidental and Intentional Learning in Taking up a Foreign Language
}

\author{
Yishan $\mathrm{Lu}^{1, *}$ \\ ${ }^{1}$ School of atmospheric science, Lanzhou University, Gansu, 730000, China \\ ${ }^{*}$ Corresponding author. Email: luysh19@lzu.edu.cn
}

\begin{abstract}
This paper reviews some identical methods in incidental learning and intentional learning and illustrates the implication of the learning strategies in learning a foreign language. In incidental learning, this paper mainly collects the former and recent research in the literature on video games, background music and cartoon contents. Except for gathering the materials from review and research literature, this paper selects a video posted on YouTube. The blogger promulgates a new theory on map video games and analyses some of the opinions and thoughts from the blogger net citizens. And the paper exemplifies the effect that exciting and upset background music are complementary in maintaining the accuracy, complexity and fluency of a second language. In addition, watching cartoons to improve the apprehension in daily communication or professional knowledge is a double-edged sword. It is closely linked to the positive cartoon contents and time distribution in the whole process. For intentional learning, this paper introduces the former research on the efficiency of conventional teaching methods in class such as word-list, flashcards. In addition, due to the insufficiency and shortcomings in intentional learning, this paper introduces some other intentional methods by utilizing technology and reinforcing the role of teachers in the whole learning process. Apart from that, this paper defines the application and limitation of incidental learning and intentional learning methods and puts up with the improvement and implication on each method. Based on these two methods to facilitate vocabulary efficiency and retention, the paper raises a new English learning mode: Data-Driven Learning (DDL) which requires learners' high quality of thinking and recognizing skills and adds the relevant factors such as learners' vocabulary proficiency, working memory and familiarity with this new approach.
\end{abstract}

Keywords: Incidental Learning, Intentional Learning, Video Games, Data-driven Learning

\section{INTRODUCTION}

When learning a new language, it takes a long time to accumulate mistakes, lessons and experiences and repeatedly practice. Apart from time and effort, proper and efficient strategies also play an important part in the learning process. This paper is based on instructive and unconscious learning and settled on the long-term and short-term memory in vocabulary. Apart from that, it stands on the angles of supporters and learners to introduce two learning strategies in language learning-incidental learning and intentional learning. This review paper covers the typical methods in these two strategies to analyze their application and limitation as well as the implication of improvement and development from these two strategies in language learning. In addition, considering the former research, this paper also represents a new learning strategy--data-driven learning, which requires a higher level of thinking skills and possesses richer resources to explore and exploit.

\section{INCIDENTAL LEARNING IN LEARNING A FOREIGN LANGUAGE}

Incidental learning is typically focused on unconscious learning and mostly occurs in informal situations in which the subjects absorb knowledge quickly and diversely. In most cases, the incidental learning methods are educational and technological, which contain cartoon and background music and video games.

\subsection{Background Music}

Varnosfaderani \& Shahaboddin mentions that happy and sad music complement the accuracy, complexity and fluency of a second language [1]. Bokiev and Ismail 
insist that teachers' beliefs and ways of using music and songs are related to the positive responses from students [2]. Although incidental learning targets unconscious learning, it is essential to search and collect proper materials to arouse students' interest to explore and learn new things on their own.

\subsection{Cartoon Contents}

Ciobanu mentions that both animated cartoons and animation films can develop children's emotional intelligence and cognitive abilities with the limitation and control of teachers [3]. Even if the cartoon discussions and flowing pictures on screens will capture the students' attention to be quiet on the storyline and communication among characters, the content and time distribution should be well organized and monitored by teachers or supporters to avoid the addiction to fiction. Since the children have little control and limitation, they are supposed to be circumscribed on how long to spend on the cartoons. In addition, Lodhi holds that the quality of cartoon content is essential to children's selfdevelopment on language and personality [4]. Filled with curiosity and desire for exploration, children are acute on the external world and more easily to try and intimate others' behaviour without much assessment. For instance, as the protagonists work together to pass through the levels and then protect their fellows from being eaten by monsters, it is likely to shape the idea that friendship is to enjoy blessings and endure misfortune together. However, as cartoon contents are covered with negative thoughts and values, children will be misguided to behave badly no matter on campus or at home.

\subsection{Video Games}

In terms of video games, Newcombe argues that video games act as an expansion of teaching materials and request a high level of learning abilities such as collaboration and independent exploration [5]. And Newcombe adds that in video games, according to different levels and ages of the learners, "customized" accessibility offers expediency for learners to understand and complete within the scope of competence [5]. Suppose the video game is designed in an unchanged mode. In that case, the higher-level learners may not meet the challenge and regard it as a waste of time. Lowerlevel learners may find it hard and consider it a consumption of patience and confidence, and curiosity. In addition, Newcombe also refers that the "identity" triggers autonomous learning and expels the learners to explore culture and ideas [5]. And DeHaan and Chen hold the view that the learners can improve their learning skills and acquire vocabulary items when enjoying playing video games $[6,7]$. In a video game, the rank of each character is equivalent to how many monsters are beaten or how difficult the game level is passed through. To get a higher level, the players are supposed to discover new paths and unlock the next level in the designed context, which allow them to comprehend the instructions and background of each shot in a foreign language and simultaneously improve themselves followed the accumulation of time and countless practices. For example, if the player intends to find the treasures, he or she needs to understand "Turn left" on the instruction board and the relevant clues and background along the road and then precisely targets the goal. And after several times of completing the missions and then getting a higher rank, they have unconsciously gained some words or phrases. DeHaan and Chen argue that language use can be improved diffusely and comprehensively in the aural and textual way $[6,7]$. For instance, the participants sometimes need to form a team. During this process, they can turn on the microphone to speak out or just type on the chat frame to discuss the routines and plans, improving their English communicative competencies.

On YouTube, a blogger named John Harris is putting up with a new conception--The Video Game Map Theory in learning a new language. Harris states that the general goal in video games map is to beat everything, including beating the bosses and meeting with many gates, trials, and gatekeepers. To move on, the players must look up subjunctive conjugation and other grammar rules in books and memorize them to pass the tests and move on. But the thing is that the players cannot fully understand those regulations even if they beat the final boss. In China, it is usual to notice that teachers will teach some uncommon words such as "igloo" and "pajamas", which seldom occur in daily conversation even if the initial purpose is identifying objects and speaking out of them in English. In that case, if the quests of each level become more direct, it may work well.

According to Harris, who knows nothing about Italian at first, he plans to memorize 1000 words used in daily life in the first step and then start talking early with natives. Using the most important words maximally shortens the preparation time and leave more space for utilizing and practising. In the end, the grammar can be put into use to correct the mistakes in former conversations. It seems that the learning process is making a coat and mastering the words and communicating with others are like stitching all fabrics and decorations. At that point, the coat can shelter from rain and wind. And learning grammar is like checking excessive threads to meet the standard. Harris also mentions, "language isn't math". It infers that the mistakes in grammar and in math are unequal. For instance, we cannot accept that one plus one equals two. But encountering a phrase like "I am like to play cat", our brain will translate it into "I like to play with cats." It does not hinder us from understanding the information. In a word, the fault tolerance of language is large, and language is basically a tool to serve for information translation. 
In addition, DeHaan and Chen also refer to the controllability in video games $[6,7]$. It means that video games are closer to the conversation in real life, and we cannot pause others' outputting words and then write them down to analyze the verb structure or past tenses and so on. Hence, even if some settings are carefully designed, the audiences cannot fully absorb and assimilate all the words or phrases, and the value of the game will be discounted. DeHaan illustrates that how to balance attending to gameplay and vocabulary at the same time is still essential [8]. That depends on learners' ability to handle multitasks.

\section{INTENTIONAL LEARNING IN VOCABULARY LEARNING}

According to Spector, intentional learning suggests a recognized learning goal, and those rational agents, including the implementer and supporter, will all get involved in the process to realize the target [9]. Hung claims that intentional learners positively utilize the necessary materials to serve a specific goal and arrange the learning missions in an orderly [10]. And in terms of intentional learning, Hung adds that it can be determined by two origins--external assistance (e.g. the tasks and quizzes designed by teachers) and internal force (the interests and self-determination), which are the combination of self-evaluation and self-determination [10]. Learners are the subjects of the whole learning process. No matter how innovative and fascinating the teaching contents are designed, if the subjects cannot stay focused on the target, the value of the content will be discounted and diminished. In addition, with the help of proper applications such as the introduction of electronic media, the learners will finally reach their destination. And the teachers can utilize the online applications to estimate and monitor students' learning levels and their ideal state to help the learners ensure their strengths and weaknesses. According to Serrano \& Huang, short-term vocabulary learning, combined with intentionally repeated reading sessions, still works well [11]. Other auxiliary skills such as listening and reading comprehension should be placed in the space to maintain longer retention memory of the vocabulary.

According to the former frameworks, Spector concludes that the technologies should add details related to particular problem-solving and decision-making tasks [9]. Hung mentions intentional vocabulary learning using digital cards individually and collaboratively in and out of class [12]. As for children in kinder gardens, it is essential to use digital cards which are designed with children's favorite cartoon characters and comprised of lovely dubbing. And children can press the button to review the word pronunciation or just listen to the chat between characters to get familiar with the sentence structure. In addition, for the small groups in class, students can work to cooperate together by testing one another or applying new words in conversation.

Webb holds that intentional learning has an immediate effect, but it cannot delay the influence for a long period [13]. And Webb adds that word-list and flashcards work more efficiently and effectively than writing and fill-in-blanks [13]. It implies that intentional learning is mainly focused on form instead of the weight of meaning. In other words, writing and fill-in-blanks are inclined to deeper thinking and creation.

In intentional learning, the extrinsic supporter not only acts as the beacon and wind director to guide and rectify direction, but they need to invoke the interest and intrinsic engagement of subjects.

\section{THE IMPLICATION OF INCIDENTAL LEARNING AND INTENTIONAL LEARNING IN VOCABULARY LEARNING}

According to the former conclusion of the relationship between incidental learning and intentional learning, Sok summarizes that "Incidental learning is presumed to entail focal attention to meaning and peripheral attention to form, while intentional learning is presumed to entail the reverse: focal attention to form and peripheral attention to meaning" [14]. Taking a new learner who reads an English book as an example. I would regard that incidental learning means that the learner looks through the whole context and intends to guess and clarify the storyline without entangling in the meaning of a single word or grammar. And incidental learning means that the learner finds the prefix and suffix to better memorize a word. But Barcroft holds that the two items should be regarded as two endpoints of a continuum [15]. Even if both ends of the continuum are not virtually linked together, they are influenced by each other indirectly. Schmitt and Won claim that intentional learning weighs more than incidental learning [16, 17]. According to Sok, combining the two kinds of learning methods benefits more than either method, and Sok insists that it works better when incidental learning follows intentional learning [14]. For instance, "Repeatedly memorizing the words, again and again, makes perfect" is popular among the group who prepare for the GRE test. If the students incidentally learn the words that are long and professional by reading a lot of journals or books, it takes much time but only partly maintains the words. As a result, according to the students who get distinction in the GRE test, the first round of only memorizing the shape and meaning quickly and roughly lays the solid foundation and repeats the procedure repeatedly. After several times, bringing the words into professional articles and contacting context to associate the meaning will eventually strengthen the understanding. Both two kinds play an important role in expanding the learning dimension, and they are similar to 
the left hand and right hand of a person. Some are skilled in using the right hand, and others are right-handed. But solely using either of the hands cannot hold a heavy rock for such a long time.

Junttila put up with four ways in learning foreign words and meanings--incidental learning, intentional learning with production, intentional learning without production, and cross-situational statistical learning [18]. And these methods are selective and applicable to different audiences. Junttila states that for children aged 5-8 years old, completing intentional missions with production can reinforce the meaning of the words [18]. As children intend to memorize the words in a particular aim, the attention will be more concentrated and purer. In addition, Junttila points that phonological processing skills and age still associate with intentional and incidental learning tasks [18].

Zandieh states that CALL (Computer Assisted Language Learning) offers language learners more alternatives to get immersed in learning and attain better consequences [19]. Not only does the computer act as a tool for beginners to boost learning and exploit knowledge, but also it narrows the possibility space and reduces the uncertainty to facilitate exploring and autonomous learning.

Even if these kinds of learning methods can be translated into different kinds of permutations and combinations, the implicit and explicit of teachers' instruction also plays an important part in students' learning. In addition, self-determination and selfconstruction are regarded as the engine's fuel to constantly push the subjects forward. Apart from that, the outcomes cannot be separated from time and effort. No matter what kind of refined methods the learners take, it is inevitable to fully engage in learning. To some extent, the payoff is closely linked to the feedback.

These two kinds of learning approaches have a direct relationship between learners and supporters. For learners, the intrinsic and internal power reinforces selfdevelopment and self-determination. Language learning is a long-term struggle and requires constant persistence. Some Chinese students who have excellent English pronunciation, so they select American TV series to intimate characters' American English pronunciation sentence by sentence to develop language sense and speaking tunes for several years. In addition, utilizing background music that possesses the sense of rhythm, the fantasy of cartoon contents and the content settings in video games will maintain the familiarity and interest in language learning. And it is also essential to set up targets and goals along the road. For instance, passing TOEFL and GRE is necessary for students who plan to study abroad. Even if the learners have met with the period of stagnation in speaking or writing, most of them will still reflect on the past learning mode and then adjust the strategy. For supporters, they are supposed to provide external and extrinsic supply to learners. For example, with the help of some monitoring measures, the supporters can assist students in setting up self-evaluation and consolidate the self-determination in the learning process, as well as rectifying the mistakes and instructing in the right direction.

Both two methods are helpful to get in touch with a new language. And the learners intend to combine these two methods together or add other innovative ideas and methods which translates the short-term memory into long-term and workable knowledge.

Apart from incidental learning and intentional learning, data-driven learning also plays a role in foreign language learning. According to Alruwaili, DDL is a communicative, task-based strategy that facilitates autonomous learning by discovering and exploring. The learners are supposed to have a high quality of thinking and to manage to utilize the data resources [20]. Lee mentions that DDL-focused methods have influenced the learners' vocabulary acquisition and long-term maintenances [21]. Men believe that there is a distinct improvement in learners' behavior on collocation production in language idiomaticity by using a datadriven learning strategy [22]. Considering the large space in corpus data, the learners will have more alternatives and options to search for the right answers by themselves. However, according to Alruwaili and Lee, the efficiency of DDL is linked to learners' vocabulary proficiency, working memory and familiarity with this new approach $[20,21]$.

\section{CONCLUSION}

In this review, the paper mainly introduces the typical methods in incidental learning and intentional learning and the implication of analyzing the two methods. Incidental learning is typically concentrated on unconscious learning and mostly occurs in informal situations, which stimulate and maintain the subjects' self-discovery and self-determination. In most cases, the incidental learning methods are educational and technological, which contain cartoon and background music and video games. Intentional learning is always arranged orderly and regularly, and learners will utilize relevant materials to realize the particular targets with the supporters monitoring and rectifying the self-evaluation. Intentional learning is used to be regarded as conventional and traditional learning methods in a class, which can be easily explained as outdated and meaningless. But it works well in short-term memory and cooperating better with up-to-date technologies such as adjusted digital flashcards.

The concentration in incidental learning is the internal meaning of the words or vocabulary, which is likely to boost long-term learning. The focus on intentional learning is language's external form and structure, which 
is efficient in short-term retentions. Both of the two methods have advantages and disadvantages, and they are targeted at different aspects. Hence, learners should weigh the extent of utilizing the methods. And combining these two methods will attain an ideal result that can translate immediately memorized words or syntactic structure into workable and applicable resources. In addition, adding other methods is also available such as data-driven learning methods. It is an innovative way to propel autonomous learning and self-discovery but requires high quality of thinking skills. Above all, other methods in incidental learning and intentional learning still exist, which are supposed to be created and improved.

\section{REFERENCES}

[1] Varnosfaderani, S. D., Shahnazari, M., \& Dabaghi, A. (2021). The influence of "happy" and "sad" background music on complexity, accuracy, and fluency of second-language speaking. Psychology of Music, 1,15 .

[2] Bokiev, D., \& Ismail, L. (2021). Malaysian ESL Teachers' Beliefs and Practices Regarding the Use of Music and Songs in Second Language Teaching. The Qualitative Report, 26 (5), 1497-1521.

[3] Ciobanu,N.R.(2019).Impact Of Cartoons On Children' s Language Learning Abilities And Emotional Intelligence Development.EDU WORLD 2018-8TH INTERNATIONAL CONFERENCE,67,898906.https://doi.org/10.15405/epsbs.2019.08.03.108

[4] Lodhi, M. A., Ibrar, S. N., Shamim, M., \& Naz, S. (2018). Linguistic analysis of selected TV cartoons and its impact on language learning. International Journal of English Linguistics, 8 (5), 247.

[5] Newcombe, J., \& Brick, B. (2017). Blending video games into language learning. International Journal of Computer-Assisted Language Learning and Teaching (IJCALLT), 7 (4), 75-89.

[6] DeHaan, J. W. (2005). Acquisition of Japanese as a foreign language through a baseball video game. Foreign Language Annals, 38 (2), 278-282.

[7] Chen, H. J. H., \& Yang, T. Y. C. (2013). The impact of adventure video games on foreign language learning and the perceptions of learners. Interactive learning environments, 21 (2), 129-141.

[8] DeHaan, J., Reed, W. M., \& Kuwanda, K. (2010). The effect of interactivity with a music video game on second language vocabulary recall. Language Learning \& Technology, 14 (2), 74-94.
[9] Spector, J. M., \& Kim, C. (2014). Technologies for intentional learning: Beyond a cognitive perspective. Australian Journal of Education, 58 (1), 9-22.

[10] Hung, W. (2014). Intrinsic and extrinsic intentional learning: The difference made by selfdetermination. Australian Journal of Education, 58 (1), 50-58.

[11] Serrano, R., \& Huang, H. Y. (2021). Time distribution and intentional vocabulary learning through repeated reading: a partial replication and extension. Language Awareness, 1-19.

[12] Hung, H. T. (2015). Intentional vocabulary learning using digital flashcards. English Language Teaching, 8 (10), 107-112.

[13] Webb, S., Yanagisawa, A., \& Uchihara, T. (2020). How Effective Are Intentional Vocabulary Learning Activities? A Meta - Analysis. The Modern Language Journal, 104 (4), 715-738.

[14] Sok, S., \& Han, Z. (2020). A study of L2 vocabulary acquisition under incidental and intentional conditions. Vigo International Journal of Applied Linguistics, (17), 113-140.

[15] Barcroft, J. (2004). Second language vocabulary acquisition: A lexical input processing approach. Foreign Language Annals, 37(2), 200-208.

[16] Schmitt, N. (2008). Review article: Instructed second language vocabulary learning. Language Teaching Research, 12(3), 329-363.

[17] Won, M. (2008). The effects of vocabulary instruction on English language learners: A metaanalysis.(Ph.D.dissertation), Texas Tech University.

[18] Junttila, K., \& Ylinen, S. (2020). Intentional training with speech production supports children' $\mathrm{s}$ learning the meanings of foreign words: a comparison of four learning tasks. Frontiers in psychology, 11, 1108 .

[19] Zandieh, Z., \& Jafarigohar, M. (2012). The Effects of Hypertext Gloss on Comprehension and Vocabulary Retention under Incidental and Intentional Learning Conditions. English Language Teaching, 5 (6), 60-71.

[20] Alruwaili, A. K. (2020). Data-driven Learning Approach for Teaching Verb-Noun Collocations in an English Foreign Language Context. Asiatic: IIUM Journal of English Language and Literature, 14 (1), 138-159.

[21] Lee, H., Warschauer, M., \& Lee, J. H. (2020). Toward the Establishment of a Data - Driven 
Learning Model: Role of Learner Factors in Corpus - Based Second Language Vocabulary Learning. The Modern Language Journal, 104 (2), 345-362.

[22] Men, H. (2020). Data-Driven Learning in Enhancing Learners, Language Idiomaticity. International Journal of Emerging Technologies in Learning (iJET), 15 (23), 27-41. 